\title{
“Não havia outra saída”: percepções de alunos evadidos sobre o abandono do curso superior ${ }^{1}$
}

\author{
Marucia Patta Bardagi ${ }^{2}$ - Universidade Luterana do Brasil, Santa Maria, Brasil \\ Cláudio Simon Hutz- Universidade Federal do Rio Grande do Sil, Porto Alegre, Brasil
}

\begin{abstract}
Resumo
A evasão no Ensino Superior é um fenômeno em expansão no Brasil, mas são poucos os estudos sobre as características da evasão e suas consequências na vida do estudante. Este estudo, parte de uma tese de doutorado sobre desenvolvimento de carreira na graduação, buscou identificar as razões da insatisfação de carreira e as percepções sobre a evasão em oito alunos evadidos, três mulheres e cinco homens entre 20 e 25 anos $(M=22,6)$, de diferentes áreas, que abandonaram o curso em diferentes momentos da graduação. Por meio de entrevistas foi possível identificar a fragilidade das escolhas iniciais, a pouca atividade exploratória e as expectativas irrealistas de carreira. Ainda, a decisão de evadir foi majoritariamente impulsiva, causada por uma insatisfação de longo prazo e não relacionada a novas escolhas de carreira. Estes resultados apontam a necessidade de estratégias que favoreçam a atividade exploratória e de serviços de apoio ao estudante universitário.

Palavras-chave: estudante universitário; evasão; ensino superior.
\end{abstract}

\section{“There was no other way": dropout students" perceptions on leaving higher education}

\begin{abstract}
University dropout is a phenomenon that is increasing in Brazil but there are few studies about the characteristics of dropout and its consequences for the student"s life. This study, part of a doctoral dissertation on vocational development in Higher Education, aimed to identify the reasons for career dissatisfaction and evasion in eight dropout students, three women and five men between 20 and 25 years-old $(M=22,6)$, undergraduates in different areas who abandoned the university at different moments. Through interviews, it was possible to identify the fragility of the initial choices, little exploratory activity, and unrealistic career expectations. Besides, the decision to drop out was mostly impulsive, caused largely by long term dissatisfaction, and unrelated with new career choices. These results pointed out that strategies that emphasize exploratory behavior are important, along with support services to college students.

Keywords: university dropout; university student; higher education.
\end{abstract}

\section{Introdução}

No Brasil, vivencia-se um período de crescimento acelerado no número de cursos e alunos no ensino superior (INEP, 2005). Entre 1990 e 2004, por exemplo, passou-se de 918 para 2013 instituições de ensino superior (IES). No entanto, apesar do maior número de ingressantes, o abandono ou trancamento de matrículas nas universidades é também um fenômeno em expansão (Ghizoni \& Teles, 2005; Magalhães \& Redivo, 1998; MEC, 2002; Mercuri \& Polydoro, 2004; Palma, Palma \& Brancaleoni, 2005). Houve uma intensificação das pesquisas acerca do tema a partir de 1995, com a criação da Comissão Especial de Estudos sobre Evasão, através da Portaria SESu/MEC, indicando uma valorização

\footnotetext{
${ }^{1}$ Trabalho oriundo de tese de doutorado da primeira autora, sob supervisão do segundo autor, com apoio da CAPES

2 Endereço de correspondência:

Rua Guilherme Alves, 450/204. Jardim Botânico, Porto Alegre, RS. CEP 90680-340.

Email: marucia.bardagi@gmail.com
}

política do fenômeno. No entanto, ele permanece ainda pouco explorado (para uma revisão de estudos sobre evasão, ver Bardagi \& Hutz, 2005).

Define-se evasão de curso como a saída do aluno de seu curso de origem, sem concluí-lo (Comissão Especial de Estudos sobre Evasão, 1996). Pesquisas indicam que os índices costumam variar, em instituições públicas ou privadas, entre $20 \%$ e 50\% (Ghizoni \& Teles, 2005; Mazzetto, Bravo \& Carneiro, 2002; MEC, 2002; Mercuri \& Polydoro, 2004; Palma \& cols., 2005). O desligamento costuma ser maior nos anos iniciais do curso (Magalhães \& Redivo, 1998; Palma \& cols., 2005; Prado, 1990; Ribeiro, 2005; Sbardelini, 1997; Veloso \& Almeida, 2001), e em um único ano, a saída tende a ser maior nos primeiros três meses. Com relação aos cursos, há menor abandono nos cursos mais valorizados, enquanto cursos menos valorizados e com baixo status apresentam os maiores índices (Mazzetto \& cols., 2002; MEC, 2002; Veloso \& Almeida, 2001). Não há consenso quanto a diferenças de gênero alguns estudos apontando predomínio de evasão 
masculina (Polydoro \& cols., 2005) e outros não mostram diferenças (Cunha, Tunes \& Silva, 2001).

As causas da evasão costumam ser variadas. Estudos têm apontado descontentamento com horários das disciplinas, falta de cursos noturnos, impossibilidade de trabalhar e estudar ao mesmo tempo (Lotufo, Souza Jr, Covacic \& Brito, 1998; Machado, Melo Filho \& Pinto, 2005; Magalhães \& Redivo, 1998; Mazzetto \& cols., 2002; Pacheco, Silva, Veloso \& Silva, 2001; Veloso \& Almeida, 2001), mau relacionamento professoraluno (Cunha \& cols., 2001; Veloso \& Almeida, 2001), pouca integração social à universidade (Polydoro, 2000; Tinto, 1997), expectativas nãocorrespondidas e falta de informações sobre curso e profissão (Cunha \& cols., 2001; Lotufo \& cols., 1998; Machado \& cols., 2005; Magalhães \& Redivo, 1998; Pacheco \& cols., 2001; Ribeiro, 2005), mau desempenho, reprovações e atraso (Cunha \& cols., 2001; Lotufo \& cols., 1998; Magalhães \& Redivo, 1998; Mazzetto \& cols., 2002; Ribeiro, 2005), problemas financeiros (Lotufo \& cols., 1998; Machado \& cols., 2005; Pacheco \& cols., 2001; Palma \& cols., 2005; Polydoro, 2000; Ribeiro, 2005), entre outros.

Uma questão importante a considerar é que a maioria dos estudos tende a ser quantitativa, a partir de surveys, com a intenção de mapear mais amplamente o fenômeno da evasão, enquanto há poucos estudos qualitativos sobre a questão. Cunha e colaboradores (2001) realizaram entrevistas com evadidos do curso de química da UNB entre 1990 e 1995 , e seus sujeitos mencionaram, com frequência, aspetos como a desorientação e o desamparo na chegada à universidade e ao curso, a falta de informação, o despreparo para lidar com a diferença entre o ensino médio e a universidade, a dificuldade de acesso aos professores e a superficialidade nos contatos interpessoais como causas de saída. Em relação aos efeitos da decisão, os alunos referem inicialmente predominância de sentimentos de tristeza, solidão, vergonha, culpa e raiva após a saída do curso, contra somente 39\% que apontam alívio e satisfação. Outro estudo qualitativo, de Araújo e Sarriera (2004), com adultos que haviam feito um redirecionamento na carreira, identificou que sentir-se agente dos próprios projetos de vida é o que possibilita uma mudança com maior tranquilidade, mesmo que essa mudança provoque sentimentos iniciais de culpa e arrependimento. Ribeiro (2005), em um estudo com evadidos de psicologia, salientou que entre eles predominavam alunos com nível socioeconômico e cultural baixo, que não se adaptam ao habitus universitário, voltado aos públicos de classe média e alta; dessa forma, para o autor, a grande barreira para esses alunos é a dificuldade de adaptação nas dimensões espaço-temporal, socioemocional e cognitiva.

A maioria dos evadidos pretende retomar os estudos universitários (Azzi, Mercuri \& Moran, 1996; Cunha \& cols., 2001; Paredes, 1994; Polydoro, 2000; Polydoro \& cols., 2005) e a decisão de saída parece uma resposta à falta, na universidade, de um ambiente receptivo aos problemas que surgem ao longo da formação (Lotufo \& cols., 1998; Mazzetto \& cols., 2002; Veloso \& Almeida, 2001). Embora a evasão possa ser vista como positiva em muitos casos (Polydoro, 2000; Ristoff, 1999; Veloso \& Almeida, 2001), quando é resultado de um amadurecimento pessoal e vocacional e culmina com a troca de curso e a opção por uma carreira que se aproxima mais do ideal do aluno, grande parte dos estudos aponta que o abandono de curso não está associado a novas escolhas e que as novas escolhas costumam também ser bastante frágeis e pouco consistentes (Ghizoni \& Teles, 2005; Magalhães \& Redivo, 1998).

É importante ressaltar que a evasão é um aspecto substancialmente negligenciado pelas universidades e que tem sido quase totalmente debitado aos alunos (Mazzetto \& cols., 2002; Tinto, 2003), mas que deveria ser visto como um problema da instituição como um todo. Nesse sentido, tendo em vista a relevância dos estudos sobre evasão e a escassez de pesquisas qualitativas com os próprios alunos evadidos, este estudo, parte de uma tese de doutorado sobre a experiência universitária (Bardagi, 2007), propôsse a entrevistar universitários evadidos (que tenham abandonado cursos em diferentes instituições, áreas e momentos) e identificar suas percepções sobre a escolha inicial do curso, a decisão de saída e a existência de apoio institucional. Além disso, visa especificar outras variáveis que contribuíram para a saída do curso, a fim de compreender as razões para a evasão e o impacto dessa decisão na vida do estudante.

\section{Método}

\section{Participantes}

Participaram do estudo oito estudantes evadidos (três mulheres e cinco homens), com idades entre 20 e 25 anos $(M=22,62)$, a maioria deles em sua primeira graduação à época da evasão. Todos eles eram solteiros e a maioria 
(75\%) proveniente de Porto Alegre. A Tabela 1 apresenta outras características sociodemográficas dos participantes e seus códigos de identificação. $O$ critério para configurar evasão foi o abandono de curso por parte do aluno, sem retorno ao mesmo, não sendo selecionados alunos que evadiram apenas de instituição ou estavam apenas em situação de trancamento de matrícula. As formas de contato foram: a) contato com evadidos que procuraram orientação profissional na UFRGS, entrevistados antes do atendimento; e b) contato com alunos de Psicologia que tivessem evadido de outros cursos.

Tabela 1.Características sociodemográficas e acadêmicas dos participantes do estudo.

\begin{tabular}{lllllc}
\hline & Idade & Gênero & Área e curso inicial & Universidade & Semestres cursados \\
\hline P1 & 25 & F & Humanas/ Publicidade & Privada & 9 \\
P2 & 22 & M & Exatas / Eng. Elétrica & Pública & 3 \\
P3 & 21 & M & Biológicas / Medicina & Pública & 4 \\
P4 & 24 & M & Exatas / Eng. Civil & Privada & 4 \\
P5 & 22 & M & Humanas / Administração & Privada & 3 \\
P6 & 24 & F & Humanas/Rel. Públicas & Pública & 5 \\
P7 & 23 & M & Exatas / Eng. Civil & Pública & 7 \\
P8 & 20 & F & Artes / Artes Plásticas & Pública & 1 \\
\hline
\end{tabular}

\section{Instrumento e procedimentos}

Foi utilizada para coleta de dados uma entrevista semiestruturada, abordando três macrocontextos da experiência do evadido: Primeira Escolha - questões abordando a forma como o aluno escolheu o curso, as expectativas existentes em relação ao curso, à universidade e à profissão, o processo de exploração vocacional empregado (busca de experiências e informações); Vivência Acadêmica - questões relativas à adaptação ao curso e aos colegas, à rotina de atividades desenvolvidas pelo aluno e ao desempenho escolar; Evasão, Situação Atual e Possíveis Intervenções - questões relativas à decisão de sair, à avaliação da decisão tomada e às possíveis intervenções que teriam sido úteis durante o curso. Uma versão preliminar da entrevista foi submetida a juízes (especialistas em orientação profissional) e um estudo piloto indicou que as questões permitiam boa compreensão e a identificação dos temas de interesse. As entrevistas foram agendadas conforme a disponibilidade dos participantes, que assinaram um Termo de Consentimento Livre e Esclarecido ao confirmarem sua participação como voluntários na pesquisa. Quando solicitado pelo participante, foi feito um encaminhamento para atendimento em orientação profissional.

\section{Resultados}

Os dados foram submetidos à análise de conteúdo (Bardin, 1977), que seguiu três etapas: $\left.1^{\mathrm{a}}\right)$ levantamento dos principais temas emergentes para a compreensão da experiência dos estudantes; $\left.2^{a}\right)$ recorte do material em unidades de sentido e categorização; $3^{a}$ ) inferências e interpretação. Para este artigo, entre os temas estabelecidos para análise, serão discutidos três: escolha inicial e informação profissional, expectativas iniciais e decisão de saída e possíveis intervenções.

\section{1) Escolha inicial e informação profissional}

Todos os participantes relataram sensação de liberdade de escolha, sem percepção de pressões explícitas em relação às opções profissionais, mas a maioria dos participantes referiu também a sensação de obrigatoriedade de fazer uma escolha, não importa qual fosse; os participantes sentiam-se pressionados a decidir (P1, P3, P4, P6 e P8) (P1- "eu tinha que escolher alguma coisa, sabe, aí foi meio no desespero... tu é jovem, assim de classe média e parece que a única perspectiva que tu tem é sair do colégio e entrar na faculdade"; P4- "é aquilo, né, tu tem que fazer o colégio, fazer faculdade, trabalho, tudo certinho...não consigo imaginar eu não fazendo uma faculdade"). Ao avaliarem a escolha que fizeram, em sua maioria descreveram a escolha como negativa, não pela opção propriamente dita, mas pela forma como foi feita (P1, P2, P3, P4, P6 e P8), pois enfatizaram a falta de informações que possuíam, a sensação de "afobação" na hora da decisão, a percepção de não possuírem interesses genuínos na época, e os métodos inadequados de decisão; os participantes descreveram terem feito escolhas "no desespero", "sem pensar", "sem saber bem o que era", "de última hora", "sem saber dreito do que se tratava", "baseado em quase nada" e "para se livrar do problema". Apenas P5 e 
P7 relataram que à época tinham certeza de suas opções.

Quanto aos critérios utilizados na primeira escolha e os fatores decisivos para a opção, cada um indicou um critério principal, um aspecto que considerou de maior relevância. Para P1, o conhecimento que tinha sobre a atividade profissional relativa ao curso ("sabia que publicidade fazia propaganda, trabalhava com comunicação"); para P2, a facilidade na matéria ("bah, sempre gostei de matemática, sempre me dei bem em matemática, então vou tentar uma engenharia"); para P3, o interesse e o status ("na época eu me interessava muito... achava que era isso mesmo; e também é um discurso que rola, da medicina, um desafio, e tal...”); para P4, a influência do pai ("fiz vestibular para engenharia porque meu pai era engenheiro"); para P5, P6 e P8, o perfil pessoal (P5- "eu sempre achei que tinha perfil de liderança, de gostar de fazer as coisas do meu jeito, de abrir o meu próprio negócio"); e para P7, a influência do tio ("eu tinha um tio... eu tenho um tio que é engenheiro e ele parece gostar e se dar bem na engenharia"). Os participantes, em sua maioria, expressaram idéias relativas a estereótipos profissionais, ou seja, referiram como critérios nos quais basearam suas escolhas informações super generalizadas e/ou pouco consistentes com as práticas profissionais propriamente ditas (P1- "publicidade faz propaganda, isso é uma coisa palpável que eu sabia... achava que ia ser um trabalho divertido, de sempre trabalhar com grupos"; P5- "poder ser um empresário, liderar, era o que mais me atraía na administração"). Ainda, foram frequentes as verbalizações relativas à imagem social da profissão, à forma como os participantes percebiam o valor dado pelas pessoas a seus cursos de interesse (P3-"tinha toda a coisa da posição do médico... e também o valor de tu ter passado no vestibular para medicina"). O conteúdo estereotipado referia-se a modelos profissionais adotados pelos alunos (P7 - "meu tio era engenheiro... e ele tava se dando bem... daí eu achei que era legal"; P4 - "eu sempre me coloquei na obrigação de fazer alguma coisa que nem ele (pai)... ele sempre foi o melhor da turma, era prodígio, na faculdade e tal...”), a associação ente perfil pessoal e profissional (P6 - “eu era comunicativa, gostava de falar com as pessoas... daí comunicação"; P5 _"eu sempre me achei capaz de liderar, de coordenar o trabalho dos outros...tinha o perfil do administrador") e a percepção de status da profissão (P4 -"eu dava mais ênfase naquilo que o curso podia me dar, dinheiro, conforto..."; P3 _"ser médico e tal... tem todo esse clima, é difícil...”).

De forma geral, os participantes consideraram reduzida a quantidade de informações que possuíam, além de inconsistente (P1, P2, P3, P4, P6, P7, P8); apenas P5 declarou que sistematicamente foi atrás de informações, estava satisfeito com o que sabia sobre o curso e avalia como suficientes as informações que possuía na época. Esta avaliação de possuírem informações reduzidas e inconsistentes para a tomada de decisão é uma percepção atual, e não reflete o estado dos alunos no momento da primeira escolha (P1 - "não busquei muita coisa, dei uma olhada no currículo e tal... na época eu achava que eu sabia...mas faltava muita coisa, né? Eu sabia que fazia propaganda...”). Com relação à busca de informações (comportamento exploratório), os participantes em geral tinham atividades exploratórias esporádicas e não planejadas. A exceção foi P5, que relatou ter buscado propositadamente várias fontes de informação sobre o curso de administração ("quando eu comecei a ir para a profissão que eu queria, eu comecei a estudar muito sobre a matéria... eu comprei livros de administração, eu conversei com muitas pessoas, esses guias de profissões eu lia, via programas de negócios na TV...eu gostava de estudar o perfil, etc...”). Os outros participantes verbalizaram que não houve busca intencional de informações, que adquiriram conhecimentos sobre os cursos de interesse via terceiros, pelo que a mídia veiculava e por meio de material promocional. De forma geral, relataram que as informações iniciais foram satisfatórias e que não sentiram necessidade de mais dados para embasar a escolha. Foram recorrentes verbalizações de confiança excessiva nas fontes de informação, sem necessidade percebida de complementação (P4- "ele (pai) falava mais no que o curso podia me dar... mas não me lembro dele me orientando de como era o curso, o que fazia, que mercado...perguntando se eu gostava de cálculo, matemática... eu não perguntava também...não tava maduro na época...”).

\section{2) Expectativas iniciais}

Aqui, uma característica comum foi a dificuldade de mapear as expectativas, dizer o que exatamente imaginavam que aconteceria após a entrada na universidade (P1, P4, P5, P6 e P8). Com relação aos cursos, percebeu-se uma expectativa de que a entrada no curso fosse 
resolver todas as dúvidas e problemas e trazer satisfação incondicional ao aluno (P1- "pensava que ia chegar lá e ia me encontrar, sabe... eu esperava uma salvação, assim... tomara que seja isso... que seja isso que eu quero da minha vida"; P3- " eu achava que aquilo ia ser tudo...”). Outra expectativa bastante comum era de que o curso fosse se estruturar substancialmente em cima da prática (P5- "é isso, eu achava que ia sair de lá um empresário, já treinado para abrir a minha empresa... que iam me ensinar como lidar com grupos, com experiências práticas...um curso atuante, sabe..").

Com relação à universidade, os alunos descreveram expectativas generalizadas de encontrar um universo totalmente diferente do que conheciam, de mudança de status (sensação de amadurecimento, de se perceber agora como adulto por estar na faculdade, de maior independência em relação aos próprios estudos e um distanciamento maior da condição adolescente), de mudança nos relacionamentos (percepção de necessidade de formação de novos vínculos com colegas e professores, de afastamento e perda das amizades da escola e de um maior distanciamento com as pessoas no ambiente universitário) e de necessidade de postura mais autônoma (expectativa de precisarem demonstrar maior seriedade). A idéia de que a universidade seria uma nova realidade refere-se às percepções de que não haveria contato com as mesmas pessoas e ambientes a que estavam acostumados, de que o contexto universitário seria uma reestruturação total da rotina e modos de ser e agir; no entanto, essa percepção é pouco específica (P2- "a minha mãe dizia "ah, não vai ter mais essa coisa de todo mundo amigo", aí eu ficava pensando que ia ser assim, que não ia ter os meus camaradas de turma, sabe..."; P5- "eu sabia que na faculdade era todo mundo mais separado, cada grupo com os seus assuntos, mais definidos os grupos assim..."; P1- "eu achava que ia ser mais sério...eu, e os outros, e as coisas do curso...tudo"; P8- "pensei que eu ia precisar de uma dedicação assim, sabe...ser autônoma, pensar em fazer algo e fazer...que também as coisas iam ser mais organizadas lá"). Neste aspecto, P5 e P8 foram os únicos que disseram não imaginar grandes mudanças com a entrada na universidade.

Já com relação às profissões escolhidas, esta foi a área em que os participantes relataram maior dificuldade em identificar expectativas. Aqui, novamente aparecem as imagens estereotipadas das profissões, atividades e mercado de trabalho (P1 - "eu imaginava que era uma coisa muito filme, que o cliente ia lá, e todo mundo se reunia, e fazia a propaganda... era uma coisa muito idealizada que eu tinha"; P7- "eu achava que era aquele negócio, que eu ia construir obras, fazer projetos... aquele lado mais glamuroso da coisa...”).

\section{3) Saída do curso e possiveis intervenções}

Os alunos se dividiram entre aqueles cujas dúvidas existiam desde o ingresso no curso (P2, P4 e P6) e aqueles cujas dúvidas apareceram ao longo da formação (P1, P3, P5, P7 e P8); de forma geral, os alunos relataram períodos grandes de insatisfação e insegurança em relação à escolha, anteriores à evasão (P1- "eu já tava numa etapa fazia uns dois anos que eu tava pensando "é isso? é isso?"; P7- "foi desde o quarto semestre... daí vai indo... chegou no sétimo, eu não aguentei... vi que era melhor sair fora"). Para alguns a saída foi descrita como um processo gradual de afastamento, desinteresse e busca de novas atividades (P2, P3, P4 e P5), mas sem uma avaliação refletida de consequências e alternativas; os alunos foram desistindo de disciplinas, diminuindo créditos e perdendo o vínculo com o curso (P2- "eu rodei em uma, duas, aí comecei a não fazer todas, aí tranquei algumas, aí já não eram muitas... aí depois eu comecei a ir em uma só, aí quando eu decidi não fui mais em nenhuma..."). Para outros, apesar da insatisfação presente há tempo, a decisão de saída foi algo episódico, que sucedeu um acontecimento marcante (P1, P6, P7 e P8) (P1 - “eu já tava pensando, né, daí quando deu aquele estágio eu vi que não, não fui mais no estágio num dia e não fui mais na faculdade"; P7"daí quando deu aquela greve eu decidi que não ia voltar mais"). Apenas três participantes tinham novas escolhas de carreira quando evadiram (P2, P4 e P5), enquanto a maioria não havia estabelecido alternativas ou definido se esta era mesmo a melhor decisão.

Ao descreverem os fatores decisivos para a saída, houve ênfase nas questões de desconhecimento da realidade do trabalho (quando confrontados pelos conteúdos das disciplinas, estágios, mercado), problemas de relacionamento (envolvimento negativo com colegas e professores e existência de conflitos) e choque de valores e estilo de vida com as pessoas e ambientes característicos da área (quando confrontados com a filosofia de trabalho, tipos de ambientes, colegas) (P2 - "eu acho que vi como era realmente a engenharia e não quis... e tem os 
professores, que foram um bom motivo para sair"; P7- "a falta de preparação para o trabalho, o descaso dos professores com os alunos...não ter perspectiva de fazer as coisas"; P8- "o mercado de trabalho, com certeza, tu vai ver o que os artistas plásticos fazem e tu fica completamente desanimado"). Os alunos avaliaram a saída como positiva e não referiram arrependimentos, afirmando que a vida melhorou muito depois da evasão. As verbalizações enfatizam alívio por não mais lidar com os aspectos estressores do curso, a possibilidade de tempo e liberdade para pensar em outras alternativas de formação e o apoio recebido das pessoas (amigos e familiares) para a decisão tomada (P1 - "não me senti em nenhum momento infeliz de ter largado e nem arrependida... a única vez em que eu quase me arrependi foi na primeira aula de cursinho "bah, vou começar tudo de novo", mas não foi nada, só um ano e eu estava na UFRGS"; P8- "não me arrependi de ter largado nenhuma e nem penso em voltar"). $\mathrm{Na}$ época das entrevistas, a maioria dos participantes já estava novamente no Ensino Superior, à exceção de P8, que estava fazendo cursinho preparatório para o vestibular.

A maioria dos alunos declarou desconhecer coisas que a universidade pudesse fazer após a entrada no curso, mas enfatizou a oferta de orientação de carreira anterior como algo fundamental (P1, P2, P3, P4 e P8). Os alunos julgaram que processos de orientação no final do ensino médio poderiam melhorar as decisões tomadas inicialmente, especialmente se focalizarem informações sobre profissões e currículos (P3- "acho que tem que ter essa mobilidade mesmo, essa liberdade de poder sair... às vezes é bom, né, tu entrar e ter a possibilidade de sair"). Ainda, declararam achar positiva a possibilidade de evasão e transferência de curso; inclusive, mencionaram que conhecer as regras de trancamento de matrícula, normas e períodos de transferência seria importante para auxiliar o processo de decisão, sendo essa função informativa algo que a universidade pudesse fazer. Os alunos que sugeriram intervenções durante a graduação enfatizaram espaços e pessoas que pudessem acompanhar os alunos com dificuldades ou dúvidas de carreira (P5, P6 e P7). As verbalizações sugeriram um sentimento de descaso, abandono por parte da universidade, além de desconhecimento acerca de serviços, setores ou pessoas que pudessem auxiliar o aluno no momento em que ele pensa em sair do curso (P4"lá na faculdade eu não senti que tivesse alguém disposto a... não tinha ninguém com quem eu pudesse conversar sabe, sobre algum descontentamento meu, assim...então me senti perdido no curso...porque inclusive quando eu fui lá para cancelar, eles só perguntam o motivo pelo qual tu quer cancelar, tu risca ali "descontentamento"...tu só risca...eles podiam pelo menos ver o que tá acontecendo, pô, tu tá há dois anos no curso, quer sair e ninguém pergunta nada...isso aí não teve preocupação deles...”).

\section{Discussão}

A partir das entrevistas, percebe-se que apesar de muito próximos em idade e outros aspectos sociodemográficos, cada participante descreveu um processo de escolha diferente, critérios diferentes de decisão e razões também diferentes para a saída do curso. Em relação ao perfil do evadido descrito pela literatura, do aluno que sai de cursos menos tradicionais (MEC, 2002; Veloso \& Almeida, 2001) e nos semestres iniciais (Magalhães \& Redivo, 1998; Prado, 1990; Sbardelini, 1997), os participantes desta amostra se diferenciaram, pois abandonaram cursos de maior status e em semestres adiantados. Mesmo que as técnicas de amostragem tivessem a intenção de identificar alunos com experiências diversas de evasão, pode-se discordar da ideia de que o evadido tenha um perfil preferencial, sendo mais consistente pensar que a evasão é, hoje, um fenômeno generalizado na universidade, atingindo todos os cursos, áreas e tipos de alunos (Veloso \& Almeida, 2001).

Inicialmente, os resultados apontaram que há inúmeras diferenças percebidas entre o ambiente escolar e o ambiente universitário, e que algumas dessas diferenças são percebidas negativamente e auxiliam o distanciamento do aluno em relação ao curso. Com raras exceções, havia a expectativa de que a escola e a universidade seriam mundos diferentes, especialmente no que concerne à formação de vínculos e à estrutura de funcionamento, e essa expectativa era vivenciada negativamente. Os participantes demonstram, na realidade, um desconhecimento grande sobre o funcionamento universitário, suas rotinas, normas, etc. Autores como Almeida e Soares (2003) já haviam mencionado que o aluno, ao sair do ensino médio, precisa se adaptar às mudanças acadêmicas, vocacionais e sociais que ocorrem com a entrada no ensino superior. A falta de informações sobre a nova estrutura faz com que essa mudança seja 
vivenciada não como uma transição, mas como uma ruptura abrupta. Nesse sentido, uma primeira possibilidade de facilitar a transição escolauniversidade é conversar e informar os alunos sobre as características peculiares e diferenças entre os dois contextos, preparando o aluno para as mudanças a serem enfrentadas. Essa tarefa poderia ser assumida pela universidade, como estratégia de acolhimento do aluno, com o intuito de dirimir crenças irracionais sobre o funcionamento institucional e facilitar a integração (Veloso \& Almeida, 2001). Entre as diferenças percebidas positivamente, pode-se citar a percepção de que será possível ter mais autonomia na universidade do que havia na escola; a expectativa de maior independência é avaliada como algo bom, uma conquista de quem entra na universidade. Nesse sentido, a saída da escola é vista como um passo em direção à adultez e a maior responsabilidade.

Quando avaliam as escolhas iniciais, os alunos são unânimes em dizer que "escolheram errado", supondo que se tivessem "escolhido certo" não teriam se decepcionado ou tido razões para evadir; ainda, recomendam como intervenções, em maioria absoluta, o auxílio à primeira escolha, o que configura uma supervalorização da decisão inicial. Como apontam Morgan e Ness (2003), estudantes que recebem a mensagem de que mudanças de carreira são normais e esperadas podem mais facilmente engajar-se em mudanças e manter sua autoeficácia de carreira; do contrário, podem aumentar seu senso de inadequação, dificultando a trajetória profissional e a tomada de novas decisões. Outro ponto que marca a ênfase no ensino superior é a sensação de obrigatoriedade de escolha referida pelos participantes. Os alunos, apesar de se sentirem livres para a escolha, em relação a não sofrerem pressões explícitas, não viam outra opção de profissionalização fora da universidade. O vestibular torna-se uma continuidade natural entre a vida escolar e o mundo do trabalho, a única alternativa para os alunos de classe média e alta (Magalhães \& Redivo, 1998; Sparta \& Gomes, 2005). Assim, os alunos encaram a decisão de carreira como a decisão do vestibular, realizando a escolha para se livrar de um problema, aliviar a pressão de escolher, sem necessariamente refletir acerca de seus projetos profissionais e de vida, o que repercute negativamente na forma como as decisões são tomadas.

Os participantes salientaram a falta de reflexão, a impulsividade, o estado de estresse em que se encontravam, a falta de informações consistentes e o excesso de confiança em informações vindas de uma única fonte (pessoal ou material). Essas verbalizações apontam para um quadro de fragilização da escolha inicial, com pouca segurança em relação à decisão (Ghizoni \& Teles, 2005; Hotza \& Lucchiari, 1998; Palma \& cols., 2005). Obviamente, pode-se relacionar uma escolha inicial frágil, irrefletida, a um menor envolvimento acadêmico e maior probabilidade de frustração e evasão, uma vez que a identidade profissional e o comprometimento com o curso são aspectos importantes para a permanência (Machado \& cols., 2005; Pacheco \& cols., 2001; Ribeiro, 2005). Os alunos desta amostra adotaram uma postura mais acomodada, passiva em relação às informações profissionais, confiando excessivamente nas fontes, não buscando esclarecer dúvidas e lacunas informacionais, etc. A ansiedade relativa à escolha e ao vestibular talvez estivesse prejudicando a atividade exploratória, uma vez que a exploração gera dúvidas ao aumentar as possibilidades e/ou confrontar certezas e estereótipos, criando ambiguidade e aumentando a dificuldade de decisão. A existência de um processo sistemático de exploração de carreira não garante satisfação nem evita mudanças, mas poderia auxiliar na construção de projetos consistentes e na antecipação de barreiras que facilitam desenvolvimento da identidade profissional.

Os alunos descreveram expectativas de "gostar de tudo", "se encontrar", de uma resolução natural das dúvidas em relação à escolha. Essas expectativas utópicas são mais prováveis de serem frustradas e levar à evasão (Magalhães \& Redivo, 1998; Pacheco \& cols., 2001). Se o aluno ingressa no ensino superior consciente das diferenças em relação ao ensino médio, das lacunas da formação em relação ao mercado de trabalho e das barreiras a serem enfrentadas durante o percurso universitário, é mais provável que consiga superar as adversidades e manter sua autoeficácia e identidade de carreira. Do contrário, a probabilidade de decepção é grande e o descontentamento com a realidade universitária pode ser intransponível. Ainda, a profissão aparece nas entrevistas como uma realidade muito distante, difícil de avaliar e, em certo sentido, desconectada da experiência universitária. Esta percepção também contribui para um menor engajamento acadêmico, uma vez que o comprometimento com a carreira é um fator de permanência no curso e aumenta o 
envolvimento do aluno nas atividades e rotinas da universidade (Azzi \& cols., 1996; Mercuri \& Polydoro, 2004).

As entrevistas permitiram identificar dois perfis de insatisfação e de saída do curso. Quanto à primeira, o grupo se dividiu entre aqueles cuja insatisfação e insegurança existiam desde a entrada na universidade e a possibilidade de evasão era algo sistematicamente presente, e aqueles cuja insatisfação surgiu ao longo da graduação. Quanto à saída, o grupo se dividiu entre aqueles que gradativamente foram se desligando do curso até evadirem e aqueles cuja evasão foi um evento abrupto motivado por uma situação específica, apesar da insatisfação recorrente. Aqui se pode identificar um alerta à comunidade acadêmica: mesmo que a possibilidade de desapontamento exista para todos os alunos em todos os cursos, é preocupante o fato de que muitos dos alunos estiveram insatisfeitos com sua experiência acadêmica durante boa parte da graduação. Os alunos verbalizaram uma convivência de longo prazo com a dúvida de carreira, a dificuldade de integração acadêmica e o desejo de saída, antes que a evasão fosse implementada, confirmando os estudos que mostram índices de insatisfação e problemas emocionais aumentados entre os acadêmicos (Bardagi, Lassance \& Paradiso, 2003; Ghizoni \& Teles, 2005, entre outros).

A evasão ocorreu, na maioria dos casos, como uma alternativa extrema, irrefletida, para escapar de uma situação acadêmica considerada insustentável. O acúmulo de eventos negativos ou a ocorrência de uma situação considerada definitiva coloca o aluno diante de uma insatisfação e desgaste emocional para os quais parece não haver alternativa, ainda que não existam planos concretos para o futuro ou idéia de como a evasão vai ser percebida pela família e/ou amigos. Essa perspectiva da evasão como fuga e protesto já foi apontada na literatura (Lotufo \& cols., 1998; Mazzetto \& cols., 2002; Veloso \& Almeida, 2001), que considera a evasão como uma reação do aluno à instituição e não como um ato relacionado a uma perspectiva futura qualquer. Uma pequena parte dos participantes declarou (e, assim mesmo, alguns sem convicção) possuir uma nova escolha no momento da evasão. Dessa forma, este estudo também permite que se levante a hipótese de que a evasão não tem sido vivenciada como experiência positiva de transição de carreira ou mobilidade acadêmica, resultado do amadurecimento dos interesses ou metas profissionais (Polydoro, 2000; Ristoff, 1999;
Veloso \& Almeida, 2001), embora os participantes tenham verbalizado a intenção de voltar aos estudos superiores. O padrão desarticulado, associado com ansiedade e sem comportamento exploratório que caracterizou a evasão dos participantes, leva a uma fragilização das novas escolhas e não permite identificar que a integração ao novo curso e/ou instituição seja mais positiva e não resulte em nova evasão.

Apesar da forma como foi implementada (impulsivamente, sem novas escolhas), a evasão foi avaliada positivamente por todos, que não demonstraram arrependimento ou sentimento de culpa pela decisão tomada. Como essa avaliação foi feita tempos após a saída do curso e com quase todos os participantes já de volta ao ensino superior, é possível que inicialmente a saída tenha causado frustração, vergonha, raiva e um sentimento de incompetência (Cunha \& cols., 2001), mas que com o tempo os alunos tenham conseguido ressignificar a experiência, tornando-a mais positiva, especialmente como forma de atingir outros objetivos profissionais (Araújo \& Sarriera, 2004).

Os alunos foram consistentes em apontar a necessidade de mudanças na escolha inicial do curso e no conteúdo equivocado das informações que possuíam; nesse sentido salientaram a importância da orientação vocacional para os adolescentes antes da entrada na universidade. Nota-se que essas sugestões foram feitas como se tal processo já não fosse oferecido e estivesse à disposição dos alunos do ensino médio e outros interessados; o desconhecimento dos participantes a respeitos desses serviços é mais um indicativo do baixo comportamento exploratório. Estas sugestões ressaltam a importância que a primeira escolha tem para os alunos; uma boa escolha inicial está associada à solução dos problemas durante a graduação e é um aspecto que poderia evitar a evasão. Aqui novamente se vê que o desenvolvimento de carreira é percebido de forma mais pontual, dependendo quase que exclusivamente da escolha feita na adolescência. Entre as sugestões enfatizadas pelos alunos estão, ainda, as intervenções de acompanhamento dos processos de trancamento e desligamento de curso. Aqui aparece a sensação de abandono que o aluno sente por parte $\mathrm{da}$ instituição. Os participantes verbalizaram que a instituição não se interessa por suas dificuldades durante o curso e não se interessa em saber os motivos de saída ou auxiliar no processo de transferência ou reopção, causando frustração. Esse descaso institucional 
com a evasão foi sistematicamente enfatizado nos estudos sobre o tema (Almeida \& Soares, 2003; Cunha \& cols., 2001; Lotufo \& cols., 1998; Mazzetto \& cols., 2002; Ribeiro, 2005; Veloso \& Almeida, 2001) e determina a visão personalista que a universidade tem sobre a evasão - de que ela é uma questão pessoal do aluno sobre a qual não pode interferir.

No momento em que a universidade se implicar como responsável, entre outros fatores, pela permanência e satisfação do aluno, ela pode desenvolver estratégias que permitam identificar problemas acadêmicos com maior precocidade e oferecer intervenção preventiva ou, se isso não for possível, remedia para lidar com as questões de carreira e bem-estar psicológico dos alunos. De forma geral, a criação de espaços exclusivos para o atendimento da comunidade discente e a ampla divulgação de atividades e serviços voltados aos alunos já seriam passos importantes de reconhecimento e facilitadores da relação alunoinstituição. Neste estudo, os participantes demonstraram um grande desconhecimento de possibilidades de atendimento, pessoas ou serviços que pudessem tê-los auxiliado no processo de desligamento de curso; muitas vezes, essas oportunidades até existem, mas não se tornam parte da rotina dos alunos, não são alternativas que a comunidade acadêmica conheça e perceba como à disposição. Assim, percebe-se que a universidade tem, no mínimo, pecado ao "se apresentar" aos alunos de forma eficiente, mostrando suas instalações, equipes, serviços e atividades acadêmicas.

Com base nos resultados das entrevistas, viu-se que a evasão é uma consequência de múltiplos fatores, uma decisão tomada muitas vezes impulsivamente e sem vinculação a novas escolhas, que não representa um rompimento definitivo com a formação superior. De forma geral, este estudo permite identificar que o processo de escolha inicial do curso, quando pobre e baseado em informações estereotipadas e inconsistentes, é um facilitador potencial da evasão, pois leva a uma menor integração universitária e não cria condições de enfrentamento das dificuldades por parte do aluno. É necessário, entretanto, ressaltar que este estudo tinha por objetivo identificar o impacto de algumas variáveis para a satisfação ou insatisfação do aluno no contexto universitário, além de entender a evasão pela perspectiva do evadido, não tendo sido objetivo do estudo generalizar os resultados para todas as condições de evasão ou tipos de alunos. Nesse sentido, o abandono de curso ainda é um campo fértil de investigação e merece atenção por parte dos pesquisadores.

\section{Referências}

Almeida, L. S. \& Soares, A. P. (2003). Os estudantes universitários: sucesso escolar e desenvolvimento psicossocial. Em E. Mercuri \& S. A. J. Polydoro (Orgs.). Estudante universitário: características e experiências de formação. (pp.15-40). Taubaté, SP: Cabral.

Araújo, J. S. \& Sarriera, J. C. (2004). Redirecionamento da carreira profissional: uma análise compreensiva. Em J. C. Sarriera, K. B. Rocha \& A. Pizinato (Orgs.). Desafios do mundo do trabalbo: orientação, inserção e mudanças (pp. 135-157). Porto Alegre, RS: Edipucrs.

Azzi, R. G., Mercuri, E. \& Moran, R. C. (1996). Fatores que interferem na decisão de desistência de curso no primeiro ano de graduação. Anais do III Congresso Nacional de Psicologia Escolar, Rio de Janeiro, 144-146.

Bardagi, M. P. (2007). Evasão e comportamento vocacional de universitários. Estudos sobre o desenvolvimento de carreira na graduação. Tese de Doutorado. Porto Alegre, RS: UFRGS - Programa de Pós-Graduação em Psicologia.

Bardagi, M. P. \& Hutz, C. S. (2005). Evasão e serviços de apoio ao estudante: uma breve revisão da literatura brasileira. Psicologia Revista, 14, 279-301.

Bardagi, M. P., Lassance, M. C. P. \& Paradiso, A C. (2003). Trajetória acadêmica e satisfação com a escolha profissional de universitários em meio de curso. Revista Brasileira de Orientação Profissional, 4(1), 153- 166.

Bardin, L. (1977). Análise de conteúdo. Lisboa, Portugal: Edições 70.

Comissão Especial de Estudos sobre Evasão (1996). Diplomação, retenção e evasão nos cursos de graduação em IES públicas. Avaliação, 1(2), 55-65.

Cunha, A. M., Tunes, E. \& Silva, R. R. (2001). Evasão do curso de Química da Universidade de Brasília: a interpretação do aluno evadido. Quimica Nova, 24, 262-280.

Ghizoni, L. D. \& Teles, M. M. R. (2005). Escolha e re-escolha profissional: um estudo sobre 
estudantes universitários noturnos. Em M. C. P. Lassance, A. C. Paradiso, M. P. Bardagi, M. Sparta \& S. L. Frischenbruder (Orgs.). Intervenção e compromisso social - orientação profissional teoria e técnica (vol. 2, pp. 291-301). São Paulo, SP: Vetor.

Hotza, M. A. S. \& Lucchiari, D. H. P. S. (1998). A re-escolha profissional dos vestibulandos da UFSC de 1997. Revista da ABOP, 2, 97-110.

INEP. (2005). Censo da Educação Superior 2004: Resumo técnico. Obtido em 21 de julho de 2006 da World Wide Web: http://www.inep.gov.br/censosuperior em $21 / 07 / 2006$

Lotufo, A. D. P., Souza Jr., C., Covacic, M. \& Brito, J. M. S. (1998). Evasão e repetência na FEIS/UNESP: análise e resultados. Trabalho apresentado no XXVI Congresso Brasileiro de Ensino de Engenharia, SP. Obtido em 21 de julho de 2006 da World Wide Web: http://www.dee.feis.unesp.br/dee/docente s/publicacoes/artigo_anna_cobenge_98.pd f em 21/07/2006.

Machado, S. P., Melo Filho, J. M. \& Pinto, A. C. (2005). A evasão nos cursos de graduação de química: uma experiência de sucesso feita no Instituto de Química da UFRJ para diminuir a evasão. Química Nova, 28, S41-S43.

Magalhães, M. O. \& Redivo, A. (1998). Re-opção de curso e maturidade vocacional. Revista da $A B O P, 2,7-28$.

Mazzetto, S. E., Bravo, C. C. \& Carneiro, S. (2002). Licenciatura em química da UFC: perfil sócio-econômico, evasão e desempenho dos alunos. Quimica Nova, 25(6B), 1204 1210 .

Mercuri, E. \& Polydoro, S. A. J. (2004). O compromisso com o curso no processo de permanência/evasão no Ensino Superior: algumas contribuições. Em E. Mercuri \& S. A. J. Polydoro (Orgs.). Estudante universitário: características e experiências de formação. (pp.219-236). Taubaté, SP: Cabral.

Ministério da Educação e Cultura. Secretaria de Ensino Superior. (2002). Dados e indicadores das instituições de ensino superior - IFES 2000: Relatório final. Brasília: DF. Obtido em 21 de agosto de 2005 da World Wide Web www.mec.gov.br/sesu
Morgan, T. \& Ness, D. (2003). Career decisionmaking difficulties of first-year students. The Canadian Journal of Career Development, 2(1), 33-39.

Pacheco, I. C., Silva, J. T. A., Veloso, L. F., Silva, M. B. C. \& cols. (2001). Orientação profissional no $3^{\circ}$ grau: (re) pensando possibilidades. Anais do IV Simpósio Brasileiro de Orientação Vocacional e Ocupacional, Florianópolis, 29-37.

Palma, A. M. P. V., Palma, S. P. V. \& Brancaleoni, A. P. L. (2005). Prevenção à evasão no ensino superior: necessária implementação de orientação profissional a graduandos em desligamento. Em M. C. P. Lassance, A. C. Paradiso, M. P. Bardagi, M. Sparta \& S. L. Frischenbruder (Orgs.). Intervenção $e$ compromisso social - Orientação profissional teoria e técnica. (pp. 303-317). São Paulo, SP: Vetor.

Paredes, A. S. (1994). A evasão do terceiro grau em Curitiba. São Paulo, SP: NUPES.

Polydoro, S. A. J. (2000). O trancamento de matrícula na trajetória acadêmica do universitário: condições de saída e retorno à instituição. Tese de Doutorado. Campinas, SP: UNICAMP - Programa de Pós-Graduação em Educação.

Polydoro, S. A. J., Santos, A. A. A.., Vendramini, C. M. M., Sbardelini, E. T. B., Serpa, M. N. F. \& Natário, E. G. (2005). Percepção de estudantes evadidos sobre sua experiência no Ensino Superior. Em M. C. R. A Joly, A. A. A. Santos \& F. F. Sisto (Orgs.). Questões do cotidiano universitário. (pp.179-199). São Paulo, SP: Casa do Psicólogo.

Prado, F. D. (1990). Acesso e evasão de estudantes na graduação: a situação do curso de Física da USP. Tese de Doutorado. São Paulo, SP: USP Faculdade de Educação.

Ribeiro, M. A. (2005). O projeto profissional familiar como determinante da evasão universitária: Um estudo preliminar. Revista Brasileira de Orientação Profissional, 6(2), 5570.

Ristoff, D. I. (1999). Universidade em foco: reflexões sobre a educação superior. Florianópolis, SC: Insular.

Sbardelini, E. T. B. (1997). A re-opção de curso na Universidade Federal do Paraná. Tese de Doutorado. Ribeirão Preto, SP: USP Programa de Pós-Graduação em Saúde 
Mental da Faculdade de Medicina de Ribeirão Preto.

Sparta, M. \& Gomes, W. B. (2005). Importância atribuída ao ingresso na educação superior por alunos do ensino médio. Revista Brasileira de Orientação Profissional, 6(2), 4553.

Tinto, V. (2003). Promoting students' retention through classroom practices. Trabalho apresentado no evento "Enhancing Student Retention: Using International Policy and Practice". Obtido em 12 de dezembro de 2005 na World Wide Web http://www.staffs.ac.uk/institutes/access/ docs/Amster-paperVT(1).pdf
Tinto, V. (1997). Classrooms as communities: exploring the educational character of student persistence. Journal of Higher Education, 68(6), 599-623.

Veloso, T. C. M. A. e Almeida, E. P. (2001). Evasão nos cursos de graduação da Universidade Federal de Mato Grosso, campus universitário de Cuiabá: um processo de exclusão. Trabalho apresentado na $24^{\mathrm{a}}$ Reunião anual da ANPPED. Obtido em 21 de julho de 2002 na World Wide Web www.anped.org.br/24/tp1.htm em 21.07.02.

Recebido em maio de 2008 Reformulado em janeiro de 2009 Aprovado em fevereiro de 2009

Sobre os autores:

Marucia Bardagi é psicóloga, doutora em Psicologia (UFRGS), bolsista de pós-doutorado (CNPq) e docente do curso de Psicologia da Ulbra Santa Maria (RS) e do curso de Especialização em Psicologia Clínica da UFRGS - ênfases Avaliação Psicológica e Orientação Profissional.

Cláudio Simon Hutz é psicólogo, doutor em Psicologia pela Universidade de Iowa (EUA) e professor titular do Instituto de Psicologia da UFRGS. 